Supplement of Hydrol. Earth Syst. Sci., 22, 1775-1791, 2018

https://doi.org/10.5194/hess-22-1775-2018-supplement

(C) Author(s) 2018. This work is distributed under

the Creative Commons Attribution 4.0 License.

(c) (1)

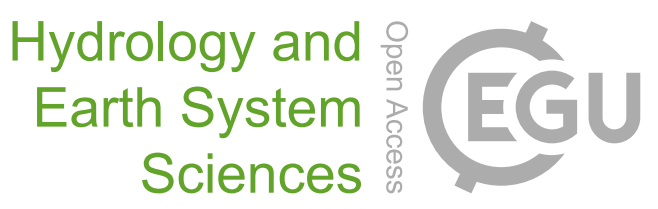

Supplement of

\title{
Mapping (dis)agreement in hydrologic projections
}

Lieke A. Melsen et al.

Correspondence to: Lieke A. Melsen (lieke.melsen@wur.nl)

The copyright of individual parts of the supplement might differ from the CC BY 4.0 License. 


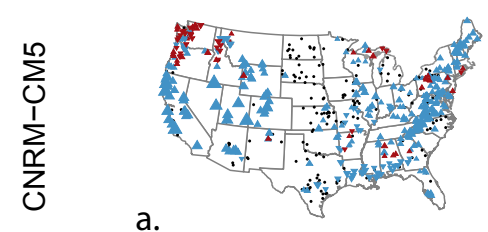

a.
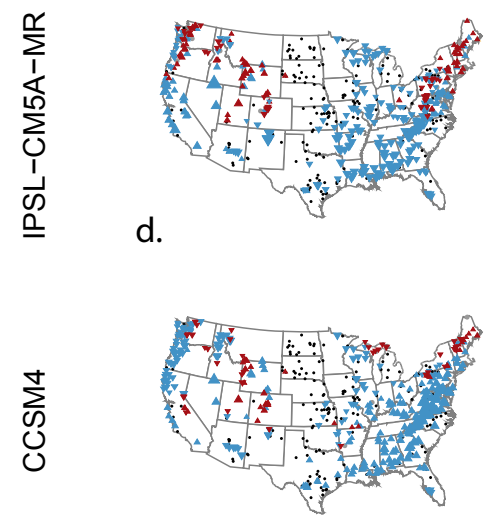

g.
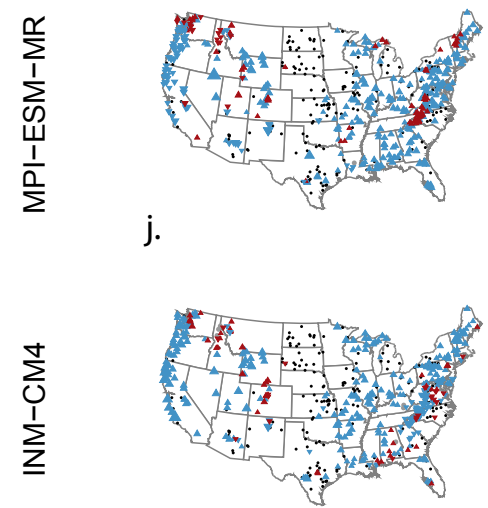

$\mathrm{m}$.

$100 \%$ agreement

$<100 \%$ agreement among the behavioural parameter sets on the sign of the change b.

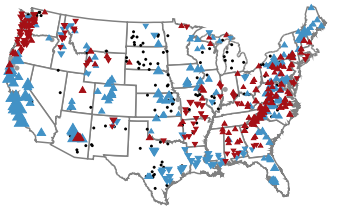

e.
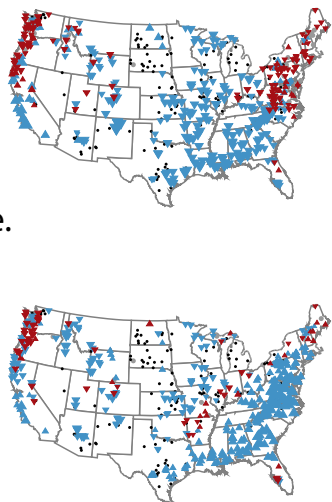

h.

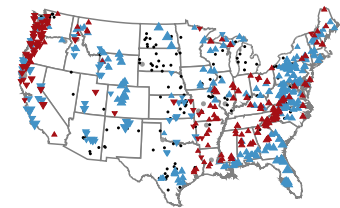

k.

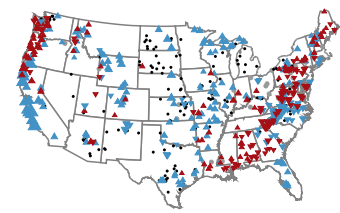

n.

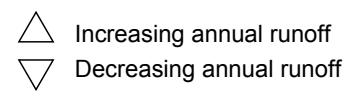

C.

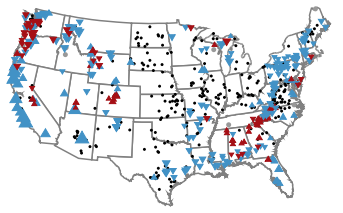

f.

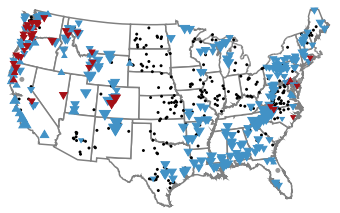

i.

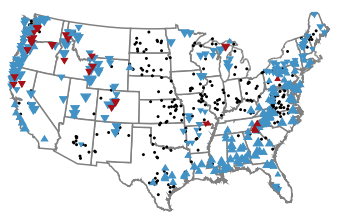

I.

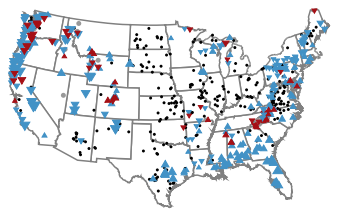

O.

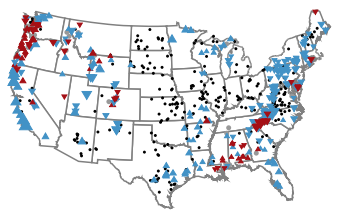

- Model non-behavioura - No significant trend

Figure A1. The agreement among the different model runs (representing different behavioural parameter sets) on the sign of the ensemble mean change in mean annual runoff for three hydrologic models (columns, VIC $=$ Variable Infiltration Capacity Model, SAC $=$ Sacramento Soil Moisture Accounting Model, HBV = Hydrologiska Byråns Vattenbalansavdelning Model) forced with five different climate models (rows). The direction of the triangle-marker shows the sign of the ensemble mean change, the size of the marker indicates the relative projected change. a) VIC forced with CNRM-CM5. b) SAC forced with CNRM-CM5. c) HBV forced with CNRM-CM5. d) VIC forced with IPSL-CM5A-MR. e) SAC forced with IPSL-CM5A-MR. f) HBV forced with IPSL-CM5A-MR. g) VIC forced with CCSM4. h) SAC forced with CCSM4. i) HBV forced with CCSM4. j) VIC forced with MPI-ESM-MR. k) SAC forced with MPI-ESM-MR. 1) HBV forced with MPI-ESM-MR. m) VIC forced with INM-CM4. n) SAC forced with INM-CM4. o) HBV forced with INM-CM4. 


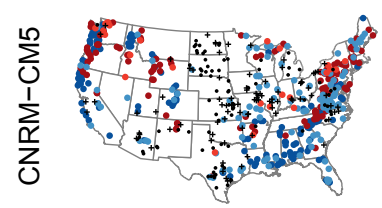

a.
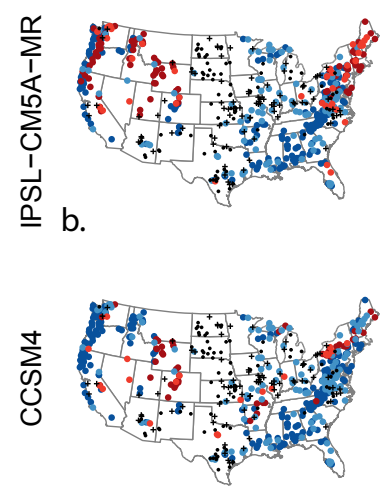

c.
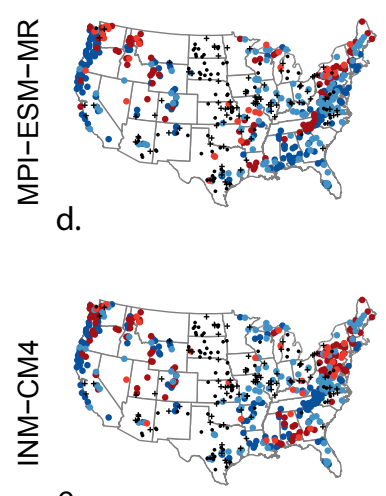

- The models agree on the sign of the change

- Two models agree, one non-behavioural

- Two models disagree, one non-behavioural

- The models disagree on the sign of the change

+ Two models are non-behavioural

- All models are non-behavioural

Figure A2. The agreement among the three hydrologic models on the sign of the ensemble mean change in mean annual runoff, forced with five different climate models. a) The three hydrologic models are forced with CNRM-CM5 data. b) The three hydrologic models are forced with IPSL-CM5A-MR data. c) The three hydrologic models are forced with CCSM4 data. d) The three hydrologic models are forced with MPI-ESM-MR data. e) The three hydrologic models are forced with INM-CM4 data. 
VIC

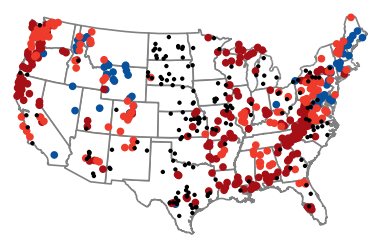

a.

- The model forced with five GCMs agrees on the sign of change

- The model forced with four GCMs agree, one disagrees

SAC

b.

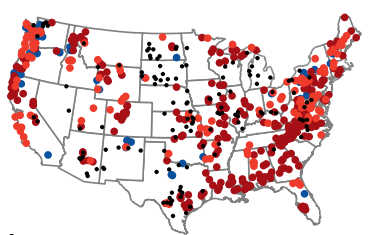

- The model forced with three GCMs agree, two disagree

- Model non-behavioural

Figure A3. The agreement on the sign of the ensemble mean change in mean annual runoff in the output from the same hydrologic model forced with five different climate models. a) Agreement when the Variable Infiltration Capacity Model (VIC) is forced with data from five different GCMs. b) Agreement when Sacramento Soil Moisture Accounting Model (SAC) is forced with data from five different climate models. c) Agreement when Hydrologiska Byråns Vattenbalansavdelning Model (HBV) is forced with data from five different GCMs. 


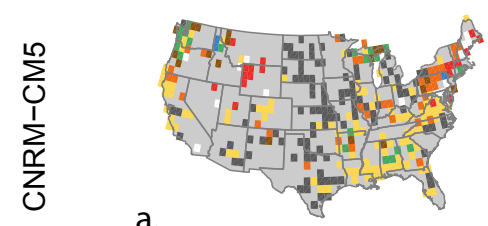

a.
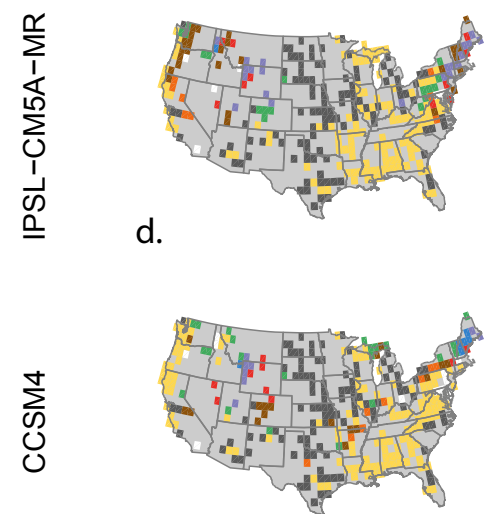

g.
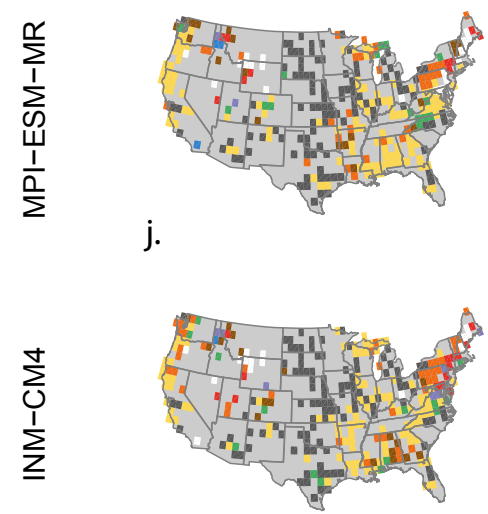

m.

$$
\begin{aligned}
& \text { Uncertainty } \\
& \text { in the sign } \\
& \text { of change } \\
& \text { introduced by: }
\end{aligned}
$$

b.
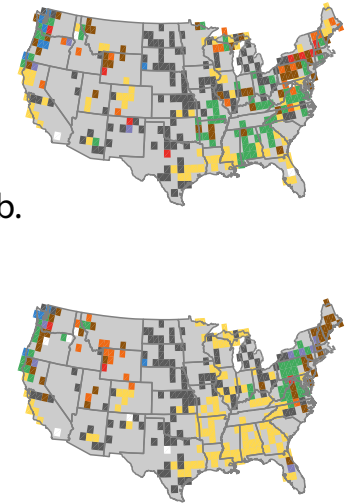

e.

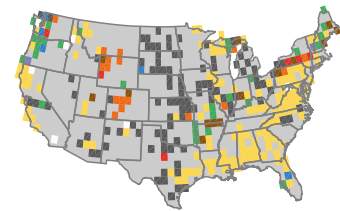

h.

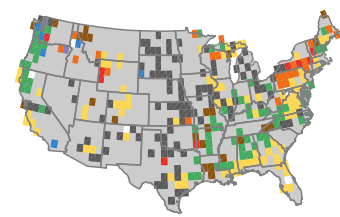

k.

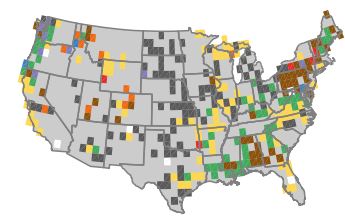

n.

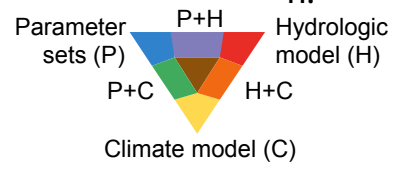

C.

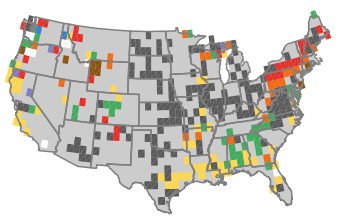

f.

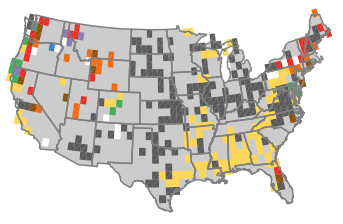

i.
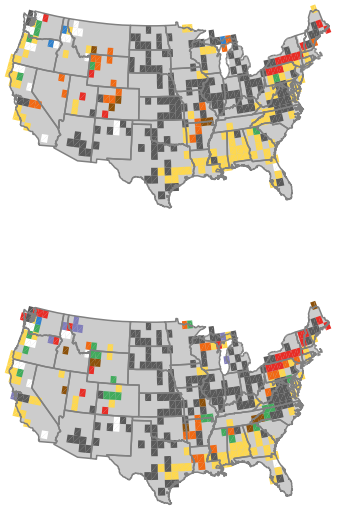

I.

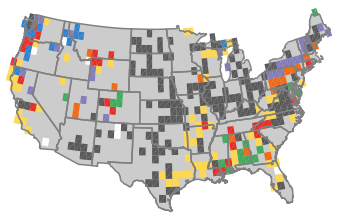

o.

$\square$ None of the investigated sources

introduced uncertainty in the sign of change

$\square$ No data

Sources of uncertainty unknown because two or three hydrological models were non-behavioural

Figure A4. Distribution of the combined investigated sources of uncertainty for mean annual runoff. Spatial coverage is obtained by determining a grid-based maximum likelihood. a) Variable Infiltration Capacity Model (VIC) was used as reference when climate model uncertainty was tested, CNRM-CM5 was used as reference when the hydrologic models were tested. b) Sacramento Soil Moisture Accounting Model (SAC) and CNRM-CM5 as reference options. c) Hydrologiska Byråns Vattenbalansavdelning Model (HBV) and CNRM-CM5 as reference options. d) VIC and IPSL-CM5A-MR as reference options. e) SAC and IPSL-CM5A-MR as reference options. f) HBV and IPSL-CM5A-MR as reference options. g) VIC and CCSM4 as reference options. h) SAC and CCSM4 as reference options. i) HBV and CCSM4 as reference options. j) VIC and MPI-ESM-MR as reference options. k) SAC and MPI-ESM-MR as reference options. 1) HBV and MPI-ESM-MR as reference options. m) VIC and INM-CM4 as reference options. n) SAC and INM-CM4 as reference options. o) HBV and INM-CM4 as reference options. 


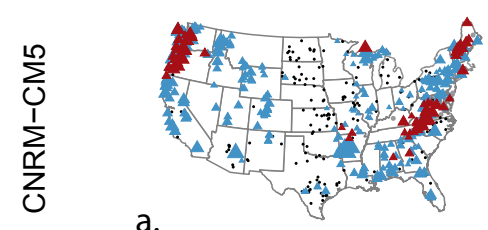

a.
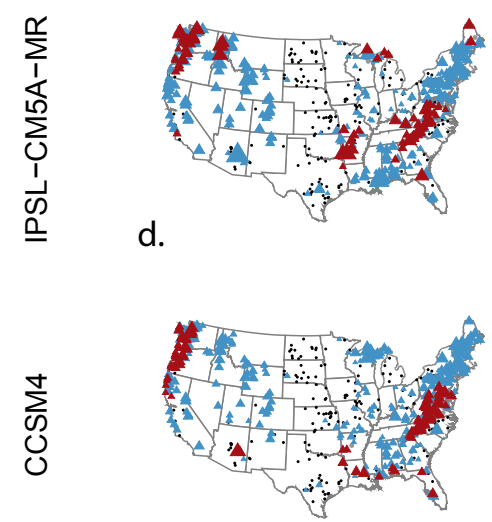

g.
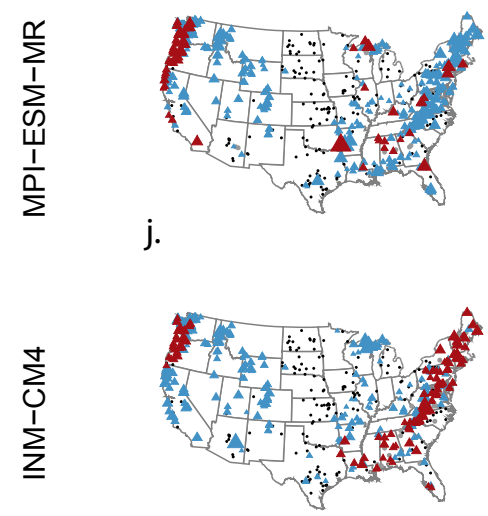

$\mathrm{m}$.

$100 \%$ agreement

$<100 \%$ agreement

among the behavioural parameter sets on the sign of the change b.

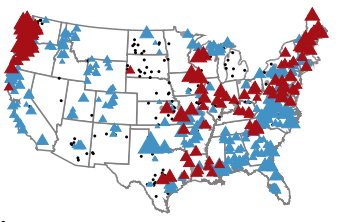

e.
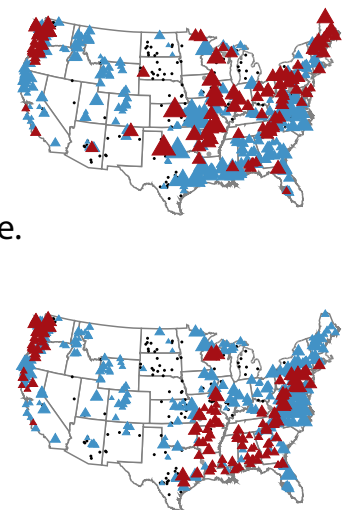

h.

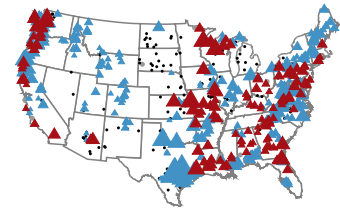

k.

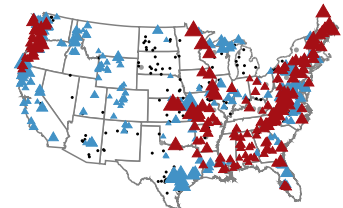

n.

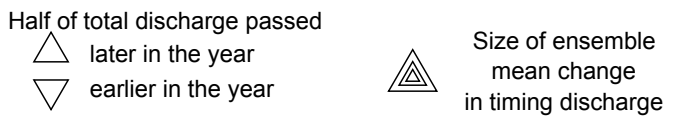

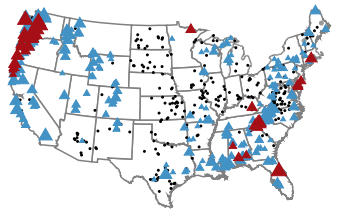

f.

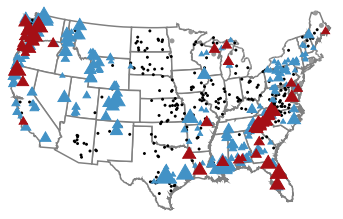

i.

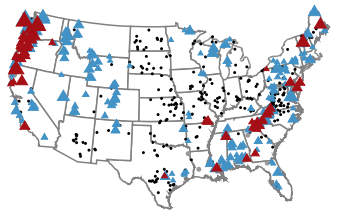

I.

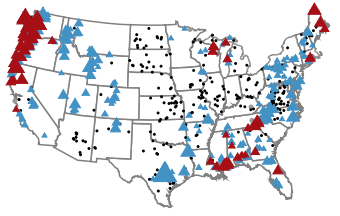

O.

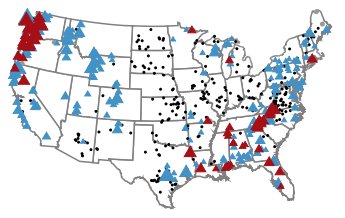

- Model non-behavioural - No significant trend

Figure B1. The agreement among the different model runs (representing different behavioural parameter sets) on the sign of change in discharge timing for three hydrologic models (columns, VIC = Variable Infiltration Capacity Model, SAC = Sacramento Soil Moisture Accounting Model, HBV = Hydrologiska Byråns Vattenbalansavdelning Model) forced with five different General Circulation Models (GCMs, rows). The direction of the triangle-marker shows the sign of the ensemble mean change, the size of the marker indicates the relative projected change. a) VIC forced with CNRM-CM5. b) SAC forced with CNRM-CM5. c) HBV forced with CNRM-CM5. d) VIC forced with IPSL-CM5A-MR. e) SAC forced with IPSL-CM5A-MR. f) HBV forced with IPSL-CM5A-MR. g) VIC forced with CCSM4. h) SAC forced with CCSM4. i) HBV forced with CCSM4. j) VIC forced with MPI-ESM-MR. k) SAC forced with MPI-ESM-MR. 1) HBV forced with MPI-ESM-MR. m) VIC forced with INM-CM4. n) SAC forced with INM-CM4. o) HBV forced with INM-CM4. 


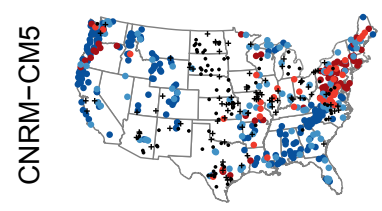

a.
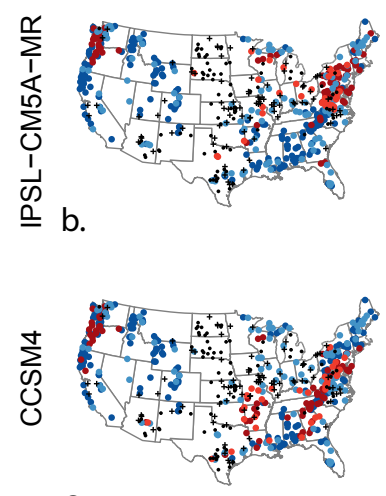

c.
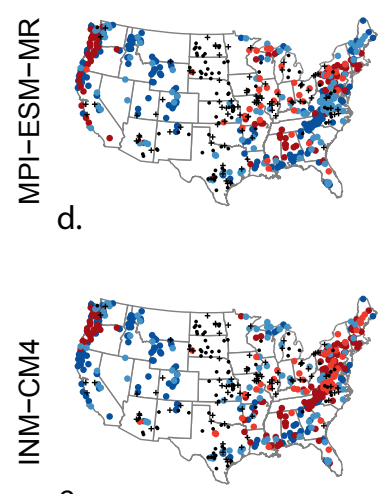

- The models agree on the sign of the change

- Two models agree, one non-behavioural

- Two models disagree, one non-behavioural

- The models disagree on the sign of the change

+ Two models are non-behavioural

- All models are non-behavioural

Figure B2. The agreement among the three hydrologic models on the sign of the ensemble mean change in discharge timing, forced with five different climate models. a) The three hydrologic models are forced with CNRM-CM5 data. b) The three hydrologic models are forced with IPSL-CM5A-MR data. c) The three hydrologic models are forced with CCSM4 data. d) The three hydrologic models are forced with MPI-ESM-MR data. e) The three hydrologic models are forced with INM-CM4 data. 
VIC

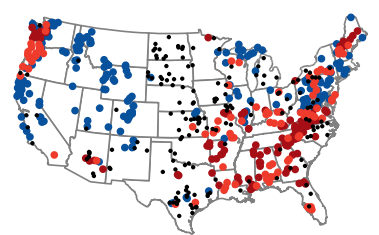

a.

- The model forced with five GCMs agrees on the sign of change

- The model forced with four GCMs agree, one disagrees
SAC

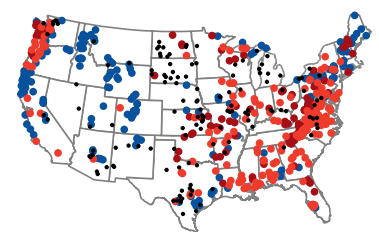

b.
HBV

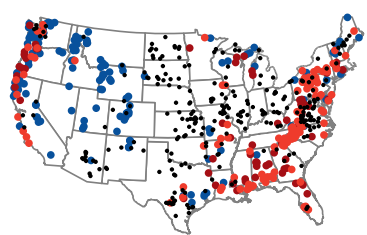

c.

- The model forced with three GCMs agree, two disagree

- Model non-behavioural

Figure B3. The agreement on the sign of the ensemble mean change in discharge timing in the output from the same hydrologic model forced with five different climate models. a) Agreement when Variable Infiltration Capacity Model (VIC) is forced with data from five different GCMs. b) Agreement when Sacramento Soil Moisture Accounting Model (SAC) is forced with data from five different climate models. c) Agreement when Hydrologiska Byråns Vattenbalansavdelning Model (HBV) is forced with data from five different GCMs. 


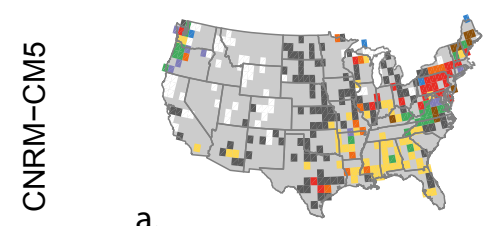

a.
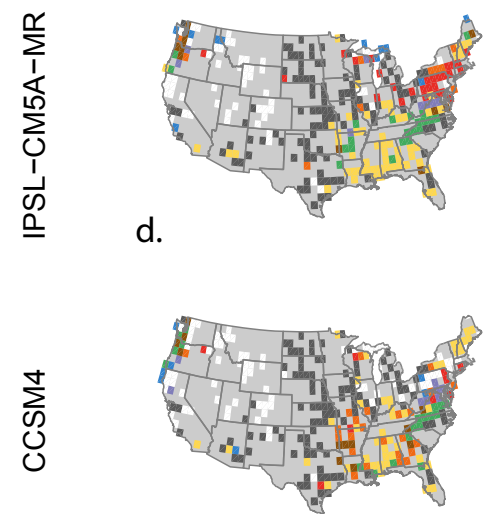

g.
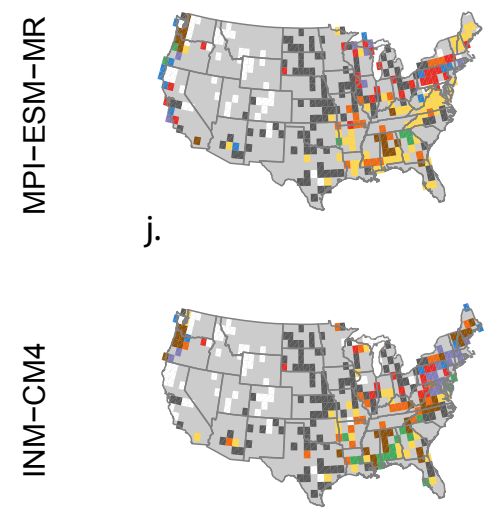

m.

$$
\begin{aligned}
& \text { Uncertainty } \\
& \text { in the sign } \\
& \text { of change } \\
& \text { introduced by: }
\end{aligned}
$$

b.
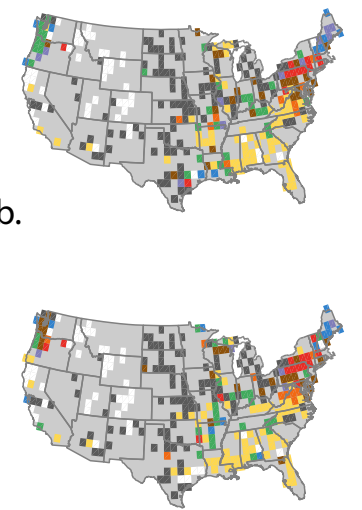

e.

h.
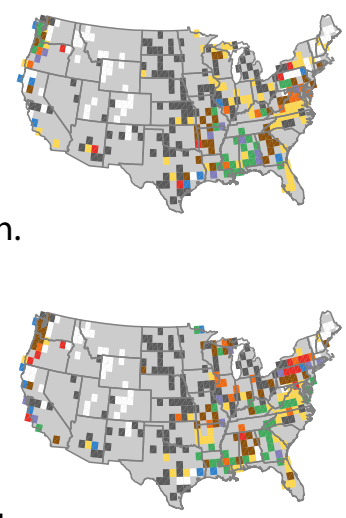

k.

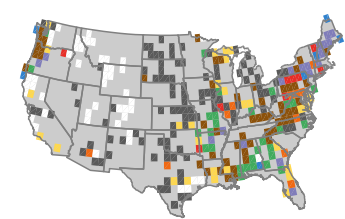

n.

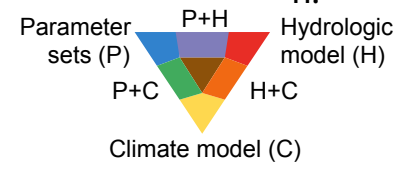

C.

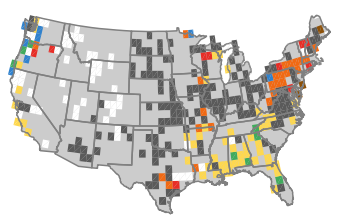

f.

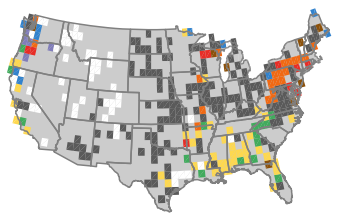

i.

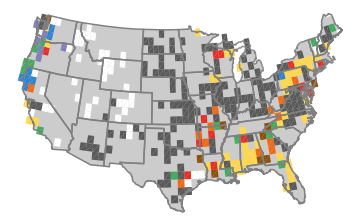

I.

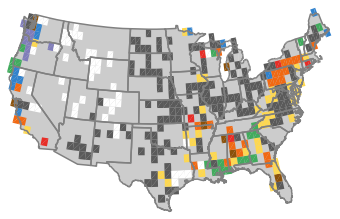

o.

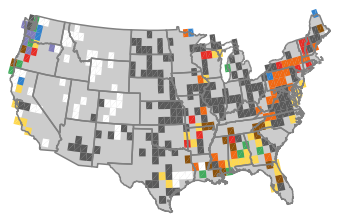

$\square$ None of the investigated sources

introduced uncertainty in the sign of change

$\square$ No data

Sources of uncertainty unknown because two or three hydrological models were non-behavioural

Figure B4. Distribution of the combined investigated sources of uncertainty for the discharge timing. Spatial coverage is obtained by determining a grid-based maximum likelihood. a) Variable Infiltration Capacity Model (VIC) was used as reference when climate model uncertainty was tested, CNRM-CM5 was used as reference when the hydrologic models were tested. b) Sacramento Soil Moisture Accounting Model (SAC) and CNRM-CM5 as reference options. c) Hydrologiska Byråns Vattenbalansavdelning Model (HBV) and CNRM-CM5 as reference options. d) VIC and IPSL-CM5A-MR as reference options. e) SAC and IPSL-CM5A-MR as reference options. f) HBV and IPSL-CM5A-MR as reference options. g) VIC and CCSM4 as reference options. h) SAC and CCSM4 as reference options. i) HBV and CCSM4 as reference options. j) VIC and MPI-ESM-MR as reference options. k) SAC and MPI-ESM-MR as reference options. 1) HBV and MPI-ESM-MR as reference options. m) VIC and INM-CM4 as reference options. n) SAC and INM-CM4 as reference options. o) HBV and INM-CM4 as reference options. 
Table C1. Selected parameters and their boundaries for the Variable Infiltration Capacity Model (VIC) model (see Methods). Parameter 1 to 7 were shown to be the most sensitive parameters based on Demaria et al. (2007); Chaney et al. (2015) and Melsen et al. (2016). Parameter 8 to 14 were selected for their impact on snow and/or evapotranspiration processes. Parameter 15 - 17 are usually hard-coded in the VIC model, but were shown to be highly sensitive in Mendoza et al. (2015) and are therefore included in the sampling. LB = lower boundary, UB = upper boundary.

\begin{tabular}{|c|c|c|c|c|c|}
\hline & Name & Unit & LB & UB & Description \\
\hline 1 & $\mathrm{~B}_{i}$ & - & $10^{-5}$ & 0.4 & Infiltration shape parameter \\
\hline 2 & $\mathrm{D}_{s}$ & - & $10^{-4}$ & 1.0 & $\begin{array}{l}\text { Fraction of } \mathrm{D}_{s, \max } \text { where non-linear } \\
\text { baseflow starts }\end{array}$ \\
\hline 3 & $\mathrm{D}_{s, \max }$ & $m m d^{-1}$ & 0.1 & 50 & Max velocity of the baseflow \\
\hline 4 & $\mathrm{~W}_{s}$ & - & 0.2 & 1.0 & $\begin{array}{l}\text { Fraction of } \mathrm{W}_{s, \max } \text { where non-linear } \\
\text { baseflow starts }\end{array}$ \\
\hline 5 & $\mathrm{Expt}_{2}$ & - & 4.0 & 30 & Exponent of the Brooks-Corey relation \\
\hline 6 & Depth $_{2}$ & $\mathrm{~m}$ & 0.1 & 3.0 & Depth of soil layer 2 \\
\hline 7 & Depth $_{3}$ & $\mathrm{~m}$ & 0.1 & 3.0 & Depth of soil layer 3 \\
\hline 8 & $\mathrm{Ts}_{\max }$ & ${ }^{\circ} \mathrm{C}$ & 0.0 & 3.0 & $\begin{array}{l}\text { Max temperature where snowfall can } \\
\text { occur }\end{array}$ \\
\hline 9 & $\mathrm{Ts} \mathrm{s}_{\min }$ & ${ }^{\circ} \mathrm{C}$ & $\mathrm{Ts}_{\max }-0.01$ & $\mathrm{Ts}_{\max }-3.0$ & $\begin{array}{l}\text { Min temperature where rainfall can oc- } \\
\text { cur }\end{array}$ \\
\hline 10 & SR & - & $5^{-5}$ & 0.5 & Surface roughness of the snow pack \\
\hline 11 & $\mathrm{RZT}_{1}$ & - & 0.5 & 2 & $\begin{array}{l}\text { Multiplication factor for rootzone thick- } \\
\text { ness layer } 1\end{array}$ \\
\hline 12 & $\mathrm{RZT}_{2}$ & - & 0.5 & 2 & $\begin{array}{l}\text { Multiplication factor for rootzone thick- } \\
\text { ness layer } 2\end{array}$ \\
\hline 13 & $\mathrm{RZT}_{3}$ & - & 0.5 & 2 & $\begin{array}{l}\text { Multiplication factor for rootzone thick- } \\
\text { ness layer } 3\end{array}$ \\
\hline 14 & $\mathrm{R}_{\min }$ & - & 0.1 & 10 & $\begin{array}{l}\text { Multiplication factor for minimum } \\
\text { stomatal resistance of the vegetation }\end{array}$ \\
\hline 15 & newalb & - & 0.7 & 0.99 & New snow albedo \\
\hline 16 & albaa & - & 0.88 & 0.99 & $\begin{array}{l}\text { Base in snow albedo function for accu- } \\
\text { mulation }\end{array}$ \\
\hline 17 & albtha & - & 0.66 & 0.98 & Base in snow albedo function for melt \\
\hline
\end{tabular}


Table C2. Selected parameters and their boundaries for the Sacramento Soil Moisture Accounting Model (SAC) model (see Methods). The parameter boundaries are based on Newman et al. (2015), the Priestley-Taylor parameter (number 18) has been adapted based on Lhomme (1997). LB = lower boundary, UB = upper boundary.

\begin{tabular}{|c|c|c|c|c|c|}
\hline & Name & Unit & LB & UB & Description \\
\hline 1 & MFAX & $\mathrm{mm}{ }^{\circ} \mathrm{C}^{-1} 6 \mathrm{~h}^{-1}$ & 0.8 & 3.0 & Max melt factor \\
\hline 2 & MFMIN & $\mathrm{mm}^{\circ} \mathrm{C}^{-1} 6 \mathrm{~h}^{-1}$ & 0.01 & 0.79 & Min melt factor \\
\hline 3 & UADJ & $\mathrm{km} 6 \mathrm{~h}^{-1}$ & 0.01 & 0.40 & $\begin{array}{l}\text { Wind adjustment factor for rain on } \\
\text { snow }\end{array}$ \\
\hline 4 & SI & $\mathrm{mm}$ & 1.0 & 3500 & $\begin{array}{l}\text { snow water equivalent for } 100 \% \text { snow } \\
\text { area }\end{array}$ \\
\hline 5 & $\mathrm{SCF}$ & - & 0.1 & 5.0 & Undercatch correction factor \\
\hline 6 & PXTEMP & ${ }^{\circ} \mathrm{C}$ & -3.0 & 3.0 & Temperature for rain/snow transition \\
\hline 7 & UZTWM & $\mathrm{mm}$ & 1.0 & 800 & $\begin{array}{l}\text { Upper zone max storage of tension wa- } \\
\text { ter }\end{array}$ \\
\hline 8 & UZFWM & $\mathrm{mm}$ & 1.0 & 800 & Upper zone max storage of free water \\
\hline 9 & LZTWM & $\mathrm{mm}$ & 1.0 & 800 & $\begin{array}{l}\text { Lower zone max storage of tension wa- } \\
\text { ter }\end{array}$ \\
\hline 10 & LZFPM & $\mathrm{mm}$ & 1.0 & 800 & Lower zone max storage of free water \\
\hline 11 & LZFSM & $\mathrm{mm}$ & 1.0 & 1000 & $\begin{array}{l}\text { Lower zone max storage of secondary } \\
\text { free water }\end{array}$ \\
\hline 12 & $\mathrm{UZK}$ & day $^{-1}$ & 0.1 & 0.7 & $\begin{array}{l}\text { Upper zone free water lateral depletion } \\
\text { rate }\end{array}$ \\
\hline 13 & LZPK & day $^{-1}$ & $1^{-5}$ & 0.025 & $\begin{array}{l}\text { Lower zone primary free water deple- } \\
\text { tion rate }\end{array}$ \\
\hline 14 & LZSK & day $^{-1}$ & $1^{-3}$ & 0.25 & $\begin{array}{l}\text { Lower zone secondary free water deple- } \\
\text { tion rate }\end{array}$ \\
\hline 15 & ZPERC & - & 1.0 & 250 & Max percolation rate \\
\hline 16 & REXP & - & 0.0 & 6.0 & Exponent of the percolation equation \\
\hline 17 & PFREE & - & 0.0 & 1.0 & $\begin{array}{l}\text { Fraction percolating from the upper to } \\
\text { the lower zone }\end{array}$ \\
\hline 18 & $\mathrm{P}-\mathrm{T}$ & - & 1.0 & 1.74 & Priestley-Taylor coefficient \\
\hline
\end{tabular}


Table C3. Selected parameters and their boundaries for the Hydrologiska Byråns Vattenbalansavdelning Model model (see Methods). The selected parameters are based on Parajka et al. (2007), the parameter boundaries have been widened based on Uhlenbrook et al. (1999) and Abebe et al. (2010). The Priestley-Taylor parameter (number 15) is based on Lhomme (1997). LB = lower boundary, UB = upper boundary.

\begin{tabular}{llllll}
\hline & Name & Unit & LB & UB & Description \\
\hline 1 & SCF & - & 0.1 & 5.0 & Snow correction factor \\
2 & DDF & $\mathrm{mm}^{\circ} \mathrm{C}^{-1}$ day $^{-1}$ & 0.04 & 12 & Degree day factor \\
3 & $\mathrm{Tr}$ & ${ }^{\circ} \mathrm{C}$ & 0.0 & 3.0 & Temperature above which precipitation \\
& & & & is rain \\
4 & $\mathrm{Ts}$ & ${ }^{\circ} \mathrm{C}$ & $\mathrm{Tr}-0.01$ & $\mathrm{Tr}-3$ & Temperature below which precipitation \\
& & & & & is snow \\
5 & $\mathrm{Tm}$ & ${ }^{\circ} \mathrm{C}$ & -3.0 & 3.0 & Temperature where melt starts \\
6 & LP & - & 0.0 & 1.0 & Evaporation reduction threshold \\
7 & FC & $\mathrm{mm}$ & 0.0 & 2000 & Max soil moisture storage \\
8 & BETA & - & 0.0 & 20 & Non-linear shape coefficient \\
9 & K0 & day & 0.0 & 2.0 & Storage coefficient of very fast response \\
10 & K1 & day & 2.0 & 30 & Storage coefficient of fast response \\
11 & K2 & day & 30 & 250 & Storage coefficient of slow response \\
12 & L & mm & 0.0 & 100 & Reservoir threshold \\
13 & PERC & mm day ${ }^{-1}$ & 0.0 & 100 & Percolation rate \\
14 & BMAX & day & 0.0 & 30 & Max baseflow of low flows \\
15 & P-T & - & 1.0 & 1.74 & Priestley-Taylor coefficient \\
\hline
\end{tabular}

VIC

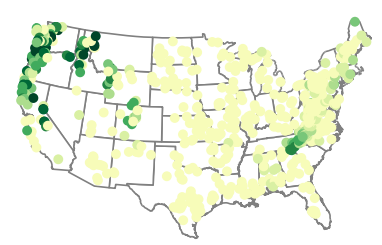

a.
SAC

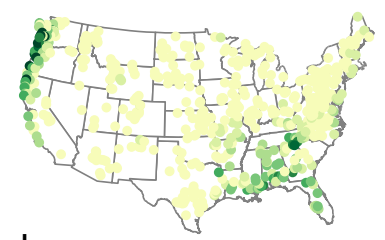

b.
HBV

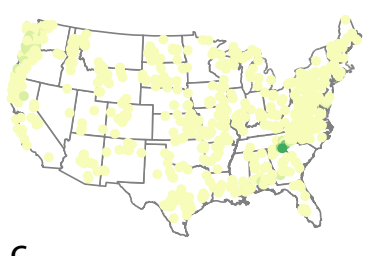

C.

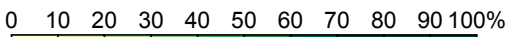

of the parameter sets classified as behavioural.

Figure C1. The percentage of parameter sets that have been classified as behavioural based on the Kling-Gupta criterion. a) for the Variable Infiltration Capacity Model (VIC), for a total parameter sample of 1800. b) for the Sacramento Soil Moisture Accounting Model (SAC), with a total parameter sample of 1900. c) for the Hydrologiska Byråns Vattenbalansavdelning Model (HBV) with a total parameter sample of 1600 . 


\section{References}

Abebe, N., Ogden, F., and Pradhan, N.: Sensitivity and uncertainty analysis of the conceptual HBV rainfall-runoff model: Implications for parameter estimation, J. Hydrol., 389, 301-310, https://doi.org/10.1016/j.jhydrol.2010.06.007, 2010.

Chaney, N., Herman, J., Reed, P., and Wood, E.: Flood and drought hydrologic monitoring: the role of model parameter uncertainty, Hydrol. Earth Syst. Sc., 19, 3239-3251, https://doi.org/10.5194/hess-19-3239-2015, 2015.

Demaria, E. M., Nijssen, B., and Wagener, T.: Monte Carlo sensitivity analysis of land surface parameters using the Variable Infiltration Capacity model, J. Geophys. Res., 112, D11113, https://doi.org/10.1029/2006JD007534, 2007.

Lhomme, J.: An examination of the Priestley-Taylor equation using a convective boundary layer model, Water Resour. Res., 33, 2571-2578, https://doi.org/10.1029/97WR01897, 1997.

10 Melsen, L., Teuling, A., Torfs, P., Zappa, M., Mizukami, N., Clark, M., and Uijlenhoet, R.: Representation of spatial and temporal variability in large-domain hydrological models: Case study for a mesoscale prealpine basin, Hydrol. Earth Syst. Sc., 20, 2207-2226, https://doi.org/10.5194/hess-20-2207-2016, 2016.

Mendoza, P. A., Clark, M., Barlage, M., Rajagopalan, B., Samaniego, L., Abramowitz, G., and Gupta, H.: Are we unnecessarily constraining the agility of complex process-based models?, Water Resour. Res., 51, 716-728, https://doi.org/10.1002/2014WR015820., 2015.

15 Newman, A., Clark, M., Sampson, K., Wood, A., Hay, L., Bock, A., Viger, R., Blodgett, D., Brekke, L., Arnold, J., Hopson, T., and Duan, Q.: Development of a large-sample watershed-scale hydrometeorological data set for the contiguous USA: data set characteristics and assessment of regional variability in hydrologic model performance, Hydrol. Earth Syst. Sc., 19, 209-223, https://doi.org/10.5194/hess19-209-2015, 2015.

Parajka, J., Merz, R., and Blöschl, G.: Uncertainty and multiple objective calibration in regional water balance modelling: case study in 320 Austrian catchments, Hydrol. Process., 21, 435-446, https://doi.org/10.1002/hyp.6253, 2007.

Uhlenbrook, S., Seibert, J., Leibundgut, C., and Rodhe, A.: Prediction uncertainty of conceptual rainfall-runoff models caused by problems in identifying model parameters and structure, Hydrolog. Sci. J., 44, 779-797, 1999. 